\title{
Highly Sensitive Electrochemical Sensor for Anticancer Drug by a Zirconia Nanoparticle-Decorated Reduced Graphene Oxide Nanocomposite
}

\author{
Manthrapudi Venu, ${ }^{\dagger, \#}$ Sada Venkateswarlu, ${ }^{\ddagger}, \#$ Yenugu Veera Manohara Reddy, ${ }^{\dagger}$ \\ Ankireddy Seshadri Reddy, ${ }^{\S \odot}$ Vinod Kumar Gupta, ${ }^{*}, \|, \perp$ Minyoung Yoon, ${ }^{*},{ }^{\ddagger}$ \\ and Gajulapalli Madhavi*, ${ }^{\dagger}$
}

\author{
${ }^{\dagger}$ Electrochemical Research Laboratory, Department of Chemistry, Sri Venkateswara University, Tirupati 517502, India \\ ${ }^{\ddagger}$ Department of Nanochemistry and ${ }^{\S}$ Department of Chemical and Biological Engineering, Gachon University, Sungnam 13120, \\ Republic of Korea \\ "Department of Applied Chemistry, University of Johannesburg, P.O. Box 524, Auckland Park 2006, South Africa \\ ${ }^{\perp}$ Department of Biological Sciences, King Abdulaziz University, Jeddah 21589, Saudi Arabia
}

\section{Supporting Information}

\begin{abstract}
Because of their large surface area and conductivity, some inorganic materials have emerged as good candidates for the trace-level detection of pharmaceutical drugs. In the present work, we demonstrate the detection of an anticancer drug (regorafenib, REG) by using an electrochemical sensor based on a nanocomposite material. We synthesized a zirconia-nanoparticle-decorated reduced graphene oxide composite $\left(\mathrm{ZrO}_{2} / \mathrm{rGO}\right)$ using a one-pot hydrothermal method. Reduction of the graphene oxide supports of the $\mathrm{Zr}^{2+}$ ions with hydrazine hydrate helped in preventing the agglomeration of the zirconia nanoparticles and in obtaining an excellent electrocatalytic response of the nanostructure $\mathrm{ZrO}_{2} / \mathrm{rGO}$-based electrochemical sensor. Structural and morphological characterization of the nanostructure $\mathrm{ZrO}_{2} / \mathrm{rGO}$ was performed using various analytical methods. A novel regorafenib (REG) electrochemical sensor was fabricated by immobilizing the asprepared nanostructure $\mathrm{ZrO}_{2} / \mathrm{rGO}$ on to a glassy carbon electrode (GCE). The resulting $\mathrm{ZrO}_{2} / \mathrm{rGO} / \mathrm{GCE}$ could be used for the rapid and selective determination of

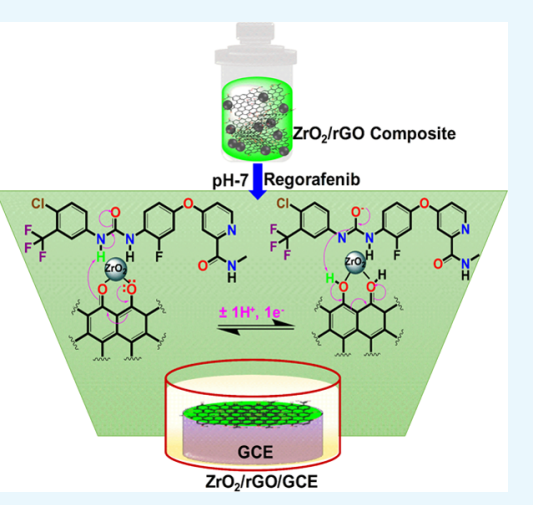
REG in the presence of ascorbic acid and uric acid. The $\mathrm{ZrO}_{2} / \mathrm{rGO} / \mathrm{GCE}$ showed a linear response for the REG analysis in the dynamic range 11-343 nM, with a remarkable lower detection limit and limit of quantifications of 17 and $59 \mathrm{nM}$, respectively. The newly developed sensor was used for the accurate determination of REG in both serum samples and pharmaceutical formulations, with satisfactory results.
\end{abstract}

\section{INTRODUCTION}

Regorafenib [4-(4-(3-(4-chloro-3-(trifluromethyl) phenyl)-3flurophenoxy)-N-ethylpicolinamide] (BAY 73-4506) is an orally bioavailable multikinase inhibitor (MKI), which also obstructs multiple tumor pathways, inhibiting targets in the receptors of the vascular endothelial growth factor 1-3 (VEGF $1-3)$, fibroblast growth factor, and platelet-derived growth factor, including the mutant oncogenic kinesis c-KIT, RET, and B-RAF. ${ }^{1,2}$ This MKI generates dynamic metabolites, which could become agglomerated, particularly in elderly, malnourished patients or in patients treated for hepatocellular carcinoma, as in the case of other MKIs. ${ }^{3}$ Oral drugs present high protein binding and poor bioavailability and are effectively metabolized by CYP3A4 and UGT1A9 in the liver., ${ }^{4}$ Regorafenib (REG), being orally administrated, may lead to drug interactions and major toxicities that may lead to early termination of the treatment and thus diminish its chances of success. It is important to maintain the benefits of these treatments, particularly in the elderly or in patients treated for metastatic colon cancer and gastrointestinal tumors, which is approved by FDA. ${ }^{6-11}$ The most serious adverse reaction was drug-induced hepatotoxicity, and a black box warning has been indicated by the US-FDA. ${ }^{12}$ Thus, the detection of this anticancer active drug is extensively important and a universal challenge. Some of the sophisticated analytical methods such as high-performance liquid chromatography (HPLC), ${ }^{13}$ liquid chromatography-mass spectrometry (LC-MS), ${ }^{14-19}$ and spectrophotometry ${ }^{20}$ are used for the detection of REG in urine, plasma, and other biological samples. However, the aforementioned methods are highly expensive, time-consuming, difficult procedures and require skilled personnel for the specimen, which restricts their particle application. To mitigate

Received: August 22, 2018

Accepted: October 24, 2018

Published: November 1, 2018 
Scheme 1. Synthesis of the $\mathrm{ZrO}_{2} / \mathrm{rGO}$ Nanocomposite for the Electrochemical Sensing of REG

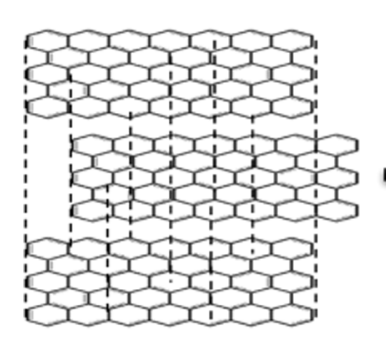

Graphite

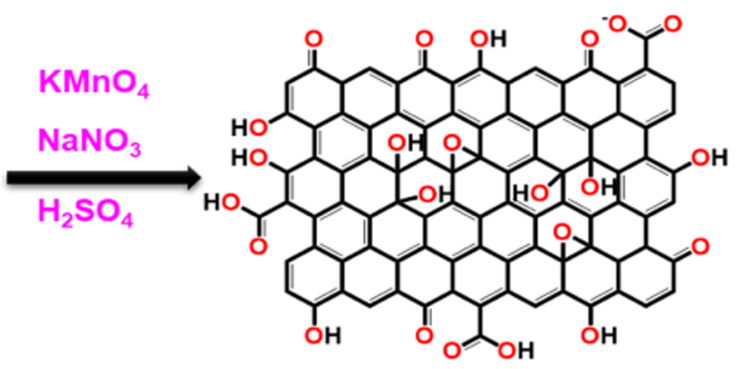

Exfoliated Graphene Oxide

\section{$\mathrm{NH}_{2} \mathrm{NH}_{2} \cdot \mathrm{H}_{2} \mathrm{O}$}

$\mathrm{ZrOCl}_{2} \cdot 8 \mathrm{H}_{2} \mathrm{O}$

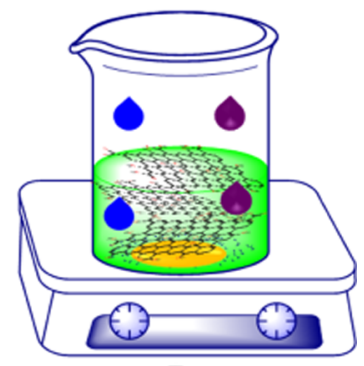

$180^{\circ} \mathrm{C}$

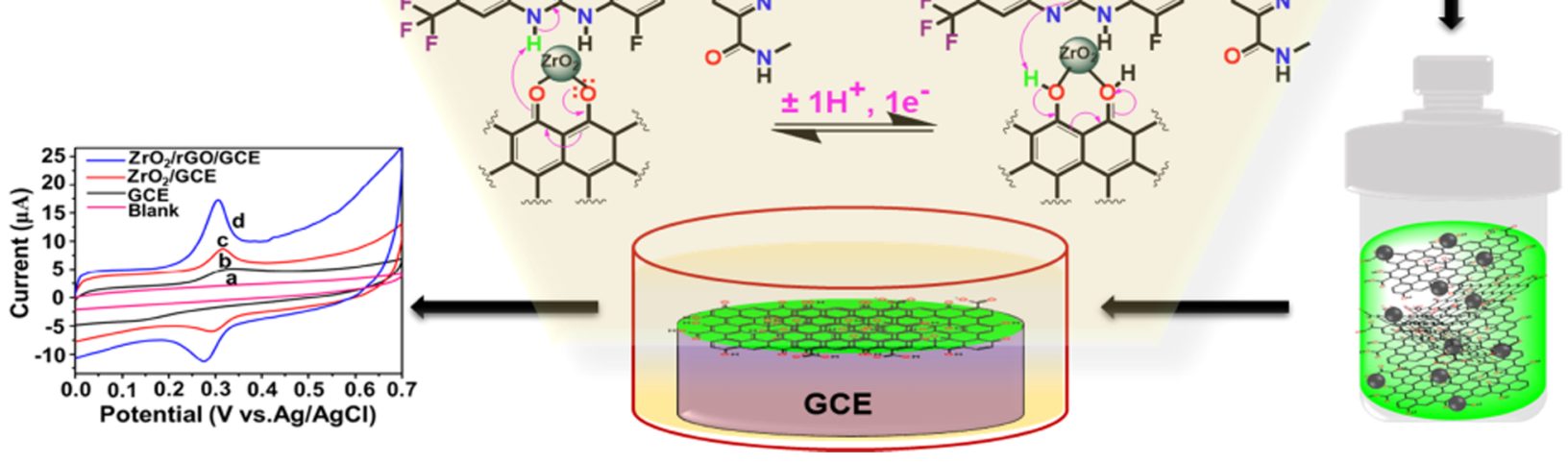<smiles>CC(C)N(C)C1CCC(Cl)C(C(F)(F)F)C1</smiles>
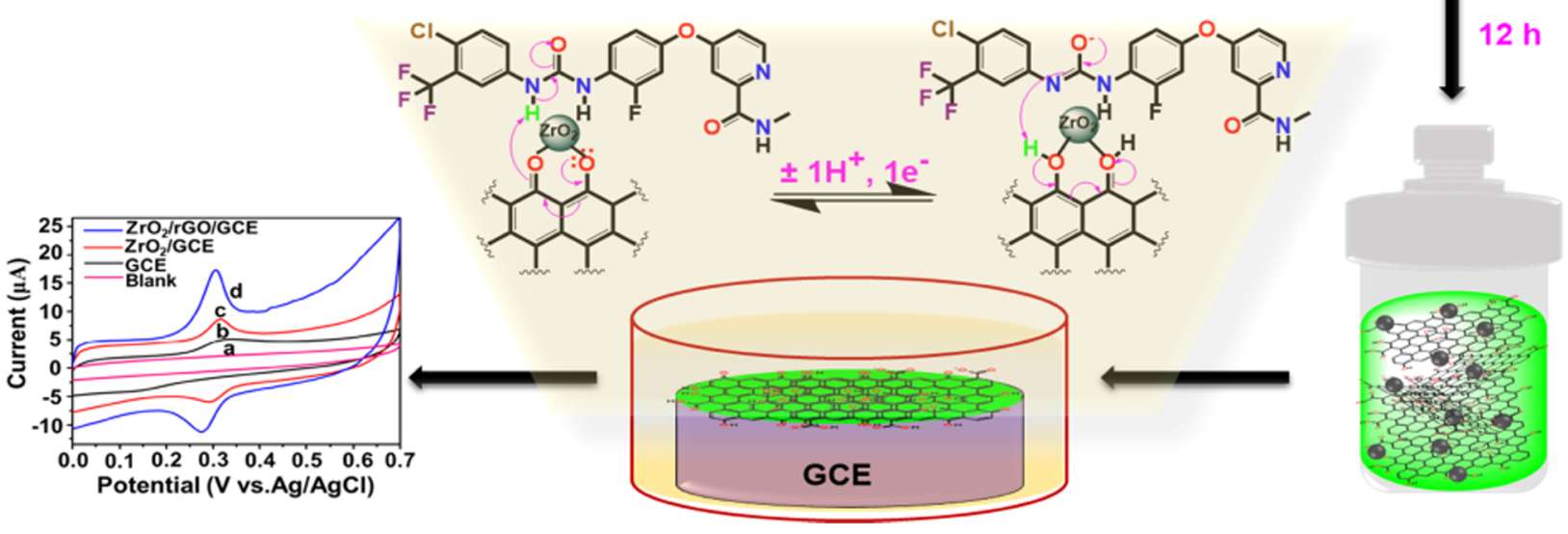

$12 \mathrm{~h}$
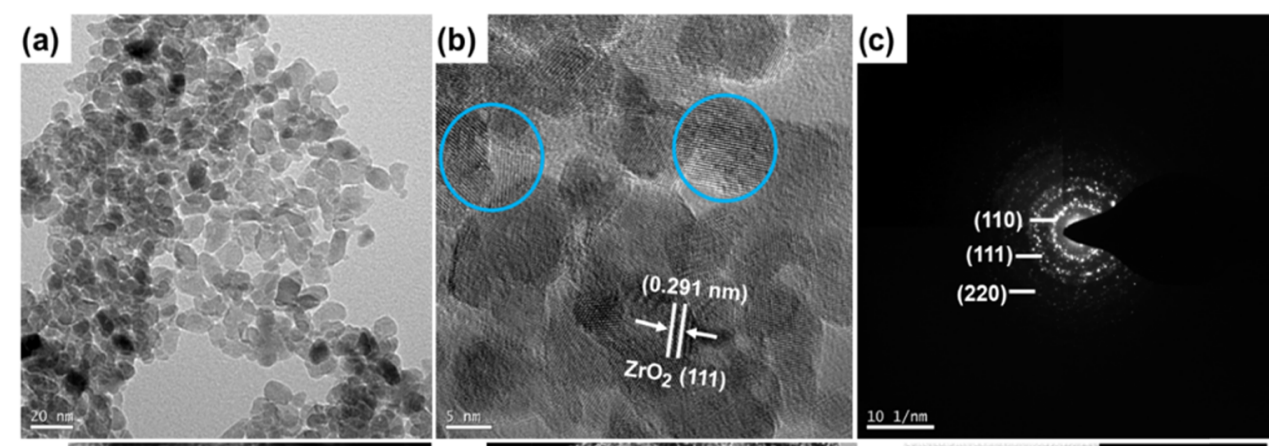

(d)
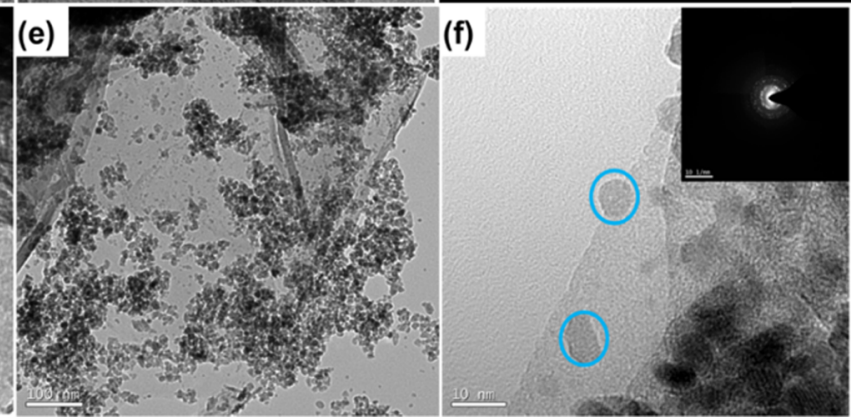

Figure 1. TEM, HRTEM, and SAED images of $(a-c)$ pristine $\mathrm{ZrO}_{2}$ and $(\mathrm{d}-\mathrm{f}) \mathrm{ZrO}_{2} / \mathrm{rGO}$ nanocomposite.

these issues, as revealed earlier, much effort has been made to develop novel substituted methods. In this concern, the electrochemical technique is one of the best methods due to its easy operation, spontaneous detection, excellent sensitivity, inexpensiveness, simple pretreatment procedure, and short analysis time for monitoring of bioelectroactive molecules and pharmaceutical drugs. However, for the detection of bioelectroactive molecules, these electrochemical methods have some analytical complications like high overpotential requirement, the reversible process at the bare and carbon paste electrode, GCE, and by-products that may be deposited on the electrode surface, which decrease its activity. Nevertheless, a familiar approach to triumph over these issues is electrodes' surface modification with various materials, like polymers, ${ }^{21-23}$ carbon materials, and metal-oxide nanoparticles. $^{24-27}$

For the last few decades, graphene oxide (GO) and reduced graphene oxide ( $\mathrm{rGO}$ ) have received significant interest owing to their excellent properties in electrochemical applications, such as good electric conductivity, large surface area, high 
chemical activity, and wide electrochemical window. ${ }^{28,29}$ Moreover, chemically, rGO is established as a promising supporting material for the uniform distribution of metal-oxide NPs. ${ }^{30-34}$

In recent years, various metal-oxide-doped graphene oxide composites have been widely used in electrochemical devices and electrocatalysis. Metal oxides, particularly, transition-metal oxides have various physicochemical properties, such as morphological structure, oxygen stoichiometry, good electrochemical conductivity, and interfacial microenvironment of the reaction. Among the transition-metal oxides, zirconium oxide nanoparticles $\left(\mathrm{ZrO}_{2}\right.$ NPs $)$ show excellent electrochemical properties, including nontoxicity, thermal stability, wide band gap, and good electrical and surface properties and are one of the most abundant metals. ${ }^{35,36} \mathrm{~A}$ critical issue in utilizing bare $\mathrm{ZrO}_{2}$ nanoparticles is that they tend to aggregate and form large clusters during their synthesis. ${ }^{37,38}$ In this connection, $\mathrm{rGO}$ is an excellent material to mitigate the agglomeration of $\mathrm{ZrO}_{2}$ NPs and subsequently enhance the electrochemical properties. Therefore, researchers have been giving dedicated extensive efforts to synthesize and explore $\mathrm{ZrO}_{2}$ decorated on rGO sheets, for example, $\mathrm{Pt} / \mathrm{ZrO}_{2}-\mathrm{RGO} / \mathrm{GCE}$ for significant enhancement of the catechol and hydroquinone oxidation, ${ }^{39}$ $\mathrm{ZrO}_{2} / \mathrm{rGO}$-based biosensor for detection of the oral cancer drug, ${ }^{40}$ and $\mathrm{Meth} / \mathrm{ZrO}_{2} / \mathrm{rGO}$-based immunosensor. ${ }^{41}$

To the best of our knowledge, this is the first example of electrochemical REG sensing in human blood serum and pharmaceutical formulations using $\mathrm{ZrO}_{2} / \mathrm{rGO} / \mathrm{GCE}$. In this work, we tried to validate such a voltammetric sensor for the detection of REG. The prepared $\mathrm{ZrO}_{2} / \mathrm{rGO} / \mathrm{GCE}$ can resolve overlapping signals from REG, uric acid (UA), and ascorbic acid (AA). In addition, the present work showed that this sensor possesses an excellent linear dynamic range (LDR) and limit of detection (LOD) for the novel REG determination (Scheme 1).

\section{RESULTS AND DISCUSSION}

Characterization of the $\mathrm{ZrO}_{2} / \mathrm{rGO}$ Nanocomposite. Transmission electron microscopy (TEM), high-resolution TEM (HRTEM), and selected area electron diffraction (SAED) analyses were conducted to examine the morphology and structure of the synthesized nanocomposite. The TEM images of the pristine $\mathrm{ZrO}_{2}, \mathrm{GO}$, and $\mathrm{ZrO}_{2} / \mathrm{rGO}$ nanocomposite are shown in Figure 1. Pristine $\mathrm{ZrO}_{2}$ nanoparticles (Figure 1a) are nearly spherical with a uniform size of size of 6-9 $\mathrm{nm}$, which is in good agreement with the calculated values based on the powder X-ray diffraction (PXRD) result. Moreover, the displaced-lattice spacing of $0.291 \mathrm{~nm}$, determined from the HRTEM images (blue circles in Figure $1 b)$ is consistent with the (111) plane of $\mathrm{ZrO}_{2}$. The pristine GO nanosheets are highly wrinkled, and the $\mathrm{ZrO}_{2}$ nanoparticles (blue circles) are well decorated and uniformly distributed on the surface of the wrinkled rGO (Figure 1d-f). The SAED patterns for $\mathrm{ZrO}_{2}$ (Figure 1c) and the $\mathrm{ZrO}_{2} / \mathrm{rGO}$ nanocomposite shown in Figure If (inset) illustrate the crystalline dots instead of amorphous rings, which indicate the polycrystalline nature of the $\mathrm{ZrO}_{2}$ nanoparticles and nanocomposite. To further confirm the formation of the nanocomposition, energy dispersive X-ray spectroscopy (EDX) analysis was employed. The presence of carbon, zirconium, and oxygen elements confirms the presence of $\mathrm{ZrO}_{2}$ on to the GO surface (Figure S3).
The phase purities of the as-synthesized $\mathrm{GO}$ and the $\mathrm{ZrO}_{2}$ / rGO nanocomposite were examined using PXRD. Figure S4a shows a diffraction peak at $2 \theta=10.7^{\circ}$, corresponding to the (001) planes of GO. The peaks of the $\mathrm{ZrO}_{2} / \mathrm{rGO}$ nanocomposite, in Figure S4b, show the existence of both tetragonal and monoclinic mixed phases, which coincide with the standard cards (JCPDS card nos. 49-1642 and 37-1484, respectively) and also show that the peak at $2 \theta=10.7^{\circ}$, in Figure S4a, has shifted to $22.4^{\circ}$ (002), indicating that GO has been reduced after treating it with the $\mathrm{ZrO}_{2}$ nanoparticles. In addition, the particle size of the $\mathrm{ZrO}_{2}$ nanoparticles was calculated using the Debye-Scherrer equation $(D=0.89 \lambda / \beta$ $\cos \theta)$, where $D, \lambda, \beta$, and $\theta$ are the average particle size, wavelength of the $\mathrm{Cu} \mathrm{K} \alpha$ irradiation, intensity at the full width at half-maximum of the diffraction peak, and diffraction angle of the (111). The average particle size of pristine $\mathrm{ZrO}_{2}$ is about $7 \mathrm{~nm}$, in good agreement with the TEM result. These results clearly confirm the formation of the $\mathrm{ZrO}_{2} / \mathrm{rGO}$ nanocomposite.

The Fourier transform infrared (FT-IR) spectra of the GO and $\mathrm{ZrO}_{2} / \mathrm{rGO}$ samples were recorded at wave numbers 500$4000 \mathrm{~cm}^{-1}$. Pristine GO has a large number of surface functional groups, as shown in Figure $\mathrm{S} 5 \mathrm{a}$, such as $\mathrm{O}-\mathrm{H}, \mathrm{C}=$ $\mathrm{O}, \mathrm{C}=\mathrm{C}$, and $\mathrm{C}-\mathrm{O}$, which are confirmed by the IR bands at $3320,1700,1604$, and $1009 \mathrm{~cm}^{-1}$, respectively. In the $\mathrm{ZrO}_{2} /$ rGO sample shown in Figure S5b, the hydroxyl, carbonyl and epoxide functional groups had disappeared and also overall peak intensities decreased significantly, which confirm reduction of pristine $\mathrm{GO}$ leads to the formation of $\mathrm{ZrO}_{2}$ / rGO nanocomposite.

The chemical composition was further confirmed by X-ray photoelectron spectrometry (XPS). The wide-survey scan spectrum of the $\mathrm{ZrO}_{2}$-doped $\mathrm{rGO}$ nanocomposite $\left(\mathrm{ZrO}_{2} /\right.$ rGO) is shown in Figure S6. The major peaks at 182.5, 284.9, and $530.2 \mathrm{eV}$ are attributed to $\mathrm{Zr} \mathrm{4p}, \mathrm{C} 1 \mathrm{~s}$, and $\mathrm{O} 1 \mathrm{~s}$, respectively. In addition, the peaks at 27,333 , and $433 \mathrm{eV}$ attributed to $\mathrm{Zr} 4 \mathrm{p}, \mathrm{Zr} \mathrm{3p}$, and $\mathrm{Zr} 3 \mathrm{~s}$, respectively. The deconvolution spectrum of the Zr 3d peak, Figure S6 (inset), shows binding energies at 182.4 and $184.9 \mathrm{eV}$ attributed to $\mathrm{Zr}$ $3 \mathrm{~d}_{5 / 2}$ and $\mathrm{Zr} 3 \mathrm{~d}_{3 / 2}$, respectively, which can be assigned to the $\mathrm{Zr}$ (IV) oxidation state. On the basis of these results, we confirmed that $\mathrm{ZrO}_{2}$ is well embedded into the wrinkled rGO.

Electrochemical Behavior of REG. Figure 2 shows the cyclic voltammograms for the electrocatalytic oxidation of REG on the bare and modified GCE electrodes, recorded in the supporting electrolyte solution (phosphate buffered saline (PBS) $0.1 \mathrm{M}, \mathrm{pH} 7.0$ ) in the presence of $0.01 \mathrm{mM}$ REG at 50 $\mathrm{mV} \mathrm{s}^{-1}$. The voltammograms recorded on the bare GCE in the absence of REG did not show any redox peaks (Figure 2a), indicating that no faradic reactions occurred on the surface of the unmodified GCE electrode. Figure $2 b$ shows that the addition of $0.01 \mathrm{mM}$ REG to the supporting electrolyte solution results in the GCE exhibiting a lowest sensitivity reversible couple peak of high separation; $\Delta E_{\mathrm{p}}=208 \mathrm{mV}$, which suggests a slow electron transfer. Figure $2 \mathrm{c}$, d shows the recognizable electrochemical response of the $\mathrm{ZrO}_{2} / \mathrm{GCE}$ and $\mathrm{ZrO}_{2} / \mathrm{rGO} / \mathrm{GCE}$, respectively, during the oxidation of 0.01 $\mathrm{mM}$ REG, which is interpreted as a result of the enhanced sensitivity, electrode surface area, and improvement of the electrochemical activity of the GO support with $\mathrm{ZrO}_{2} \mathrm{NPs}$. Figure $2 \mathrm{~d}$ shows the $\mathrm{ZrO}_{2} / \mathrm{rGO} / \mathrm{GCE}$ and reveals well-defined reversible couple peaks at about $E_{\mathrm{pa}}=275 \mathrm{mV}$ and $E_{\mathrm{pc}}=306$ $\mathrm{mV}$, attributed to the high catalytic effect during the oxidation 


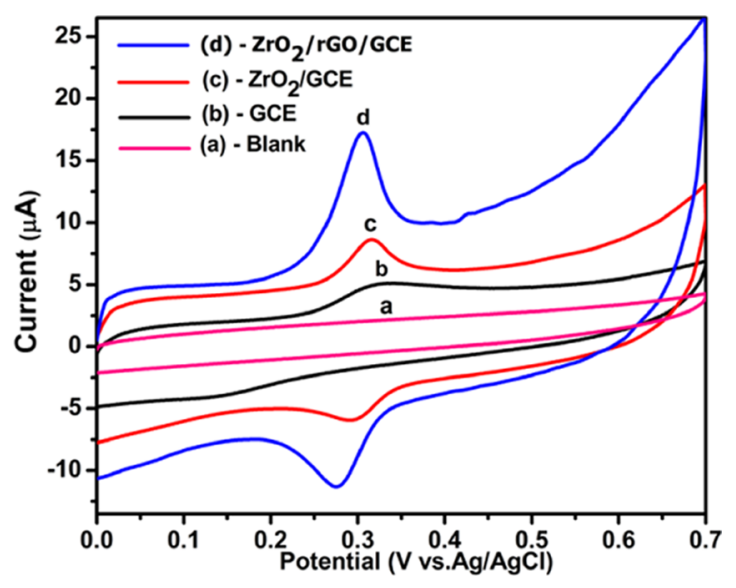

Figure 2. Cyclic voltammograms recorded in 0.1 M PBS, pH 7.0, at the scan rate of $100 \mathrm{mV} \mathrm{s}^{-1}$ (a) blank and bare GCE electrode without REG, (b) bare GCE in the presence of $0.01 \mathrm{mM}$ REG, (c) $\mathrm{ZrO}_{2}$-modified GC electrode in the presence of $0.01 \mathrm{mM} \mathrm{REG}$, and (d) $\mathrm{ZrO}_{2} / \mathrm{rGO} / \mathrm{GCE}$ in the presence of $0.01 \mathrm{mM}$ REG.

of $0.1 \mathrm{mM}$ REG. The $\mathrm{ZrO}_{2} / \mathrm{rGO} / \mathrm{GCE}$ remarkably improved the reversible couple peaks and it should be emphasized that the peak-to-peak separation, that is $\Delta E_{\mathrm{p}}$, decreased to $31 \mathrm{mV}$. Finally, the results confirmed that the prepared $\mathrm{ZrO}_{2} / \mathrm{rGO} /$ GCE significantly improves the electrocatalytic ability to oxidize REG.

Effect of $\mathrm{pH}$. The significant effects of the electrolyte $\mathrm{pH}$ on the determination of REG by electrocatalysis of $\mathrm{ZrO}_{2} /$ $\mathrm{rGO} / \mathrm{GCE}$ were studied for both current and potential. Figure 3 shows the effect of different $\mathrm{pH}$ values, in the range 5.5-8.0, investigated by differential pulse voltammetry (DPV) in a 0.01 $\mathrm{mM}$ REG solution and the relationship between $I_{\mathrm{pa}}$ and $E_{\mathrm{pa}}$ (anionic peak current and potential, respectively) with the buffer $\mathrm{pH}$. Figure $3 \mathrm{~b}$ shows that the anodic peak current of the REG electro-oxidation increases until the $\mathrm{pH}$ value becomes 7.0 and then decreases until the end of the experiment $(\mathrm{pH}$ 8.0). For this reason, the electrolytic solution with $\mathrm{pH} 7.0$ was chosen for the complete electrocatalytic study. Figure $3 \mathrm{~b}$ also shows that the formal REG potential shifts toward lower values with the increase in the supporting electrolytic solution. A better correlation coefficient was obtained for the $\mathrm{pH}$ vs $E_{\mathrm{pa}}$ which was confirmed by a slope of $0.05309 \mathrm{~V} / \mathrm{pH}\left(R^{2}=\right.$ $0.9621)$, in the range 5.5-8.0. According to the linear regression analysis, the slope of the $\mathrm{d} E_{\mathrm{p}} / \mathrm{dpH}$ being close to the theoretical value of $0.059 \mathrm{~V} / \mathrm{pH}$ indicates that the irreversible couple peaks involved the transfer of the same number of electrons and protons, ${ }^{42}$ in agreement with literature data. ${ }^{43}$ The $\mathrm{ZrO}_{2} / \mathrm{rGO} / \mathrm{GCE}$ responds to the oxidation of REG according to the mechanism presented in Scheme 2. Thus, REG-keto oxidizes to REG-enol (the amide derivative) after an exchange of one electron and one proton via $\mathrm{ZrO}_{2} / \mathrm{rGO}$ nanocomposite. ${ }^{36}$

Influence of the Scan Rate. Figure 4 a shows the influence of the scan rate, from 10 to $100 \mathrm{mV} \mathrm{s}^{-1}$, on the cyclic voltammetry $(\mathrm{CV})$ peak potential and current of $0.01 \mathrm{mM}$ REG in the presence of $0.1 \mathrm{M} \mathrm{PBS}, \mathrm{pH} 7.0$, at the $\mathrm{ZrO}_{2} / \mathrm{rGO} /$ GCE. The REG reversible couple peak current increases gradually with an increase in the scan rate. In addition, the REG oxidation and reduction peak currents $\left(I_{\mathrm{pa}}\right.$ and $\left.I_{\mathrm{pc}}\right)$ showed good linear correlation coefficients $\left(R^{2}\right)$ as a function of the square root of the scan rates of the anodic and cathodic peaks with $10-100 \mathrm{mV} \mathrm{s}^{-1}$ changing scan rates (Figure $4 \mathrm{~b}$ ), obeying the following linear regression equations

$$
\begin{aligned}
& I_{\mathrm{pa}}(\mu \mathrm{A})=2.365+0.000035 \vartheta^{1 / 2}\left(\mathrm{mV}^{1 / 2} \mathrm{~s}^{-1 / 2}\right) \\
& ;\left(R^{2}=0.9923, n=10\right) \\
& I_{\mathrm{pc}}(\mu \mathrm{A})=3.588+0.000049 \vartheta^{1 / 2}\left(\mathrm{mV}^{1 / 2} \mathrm{~s}^{-1 / 2}\right) \\
& \quad ;\left(R^{2}=0.9138, n=10\right)
\end{aligned}
$$

These results indicate that the electrochemical reactions of REG on the $\mathrm{ZrO}_{2} / \mathrm{rGO} / \mathrm{GCE}$ are diffusion-controlled processes. The estimation of the REG electrochemical parameters, at different scan rates, was made with Laviron's eqs $1-3 .^{44}$

$$
\begin{aligned}
& E_{\mathrm{pa}}=E^{0}+\frac{2.3 R T}{(1-\alpha) n F} \log \vartheta \\
& E_{\mathrm{pc}}=E^{0}-\frac{2.3 R T}{\alpha n F} \log \vartheta
\end{aligned}
$$

$$
\log k_{\mathrm{s}}=\propto \log (1-\propto)+(1-\propto) \log \propto-\log \left(\frac{R T}{n F \vartheta}\right)
$$

$$
\propto \frac{(1-\propto) n F \Delta E_{\mathrm{p}}}{2.3 R T}
$$
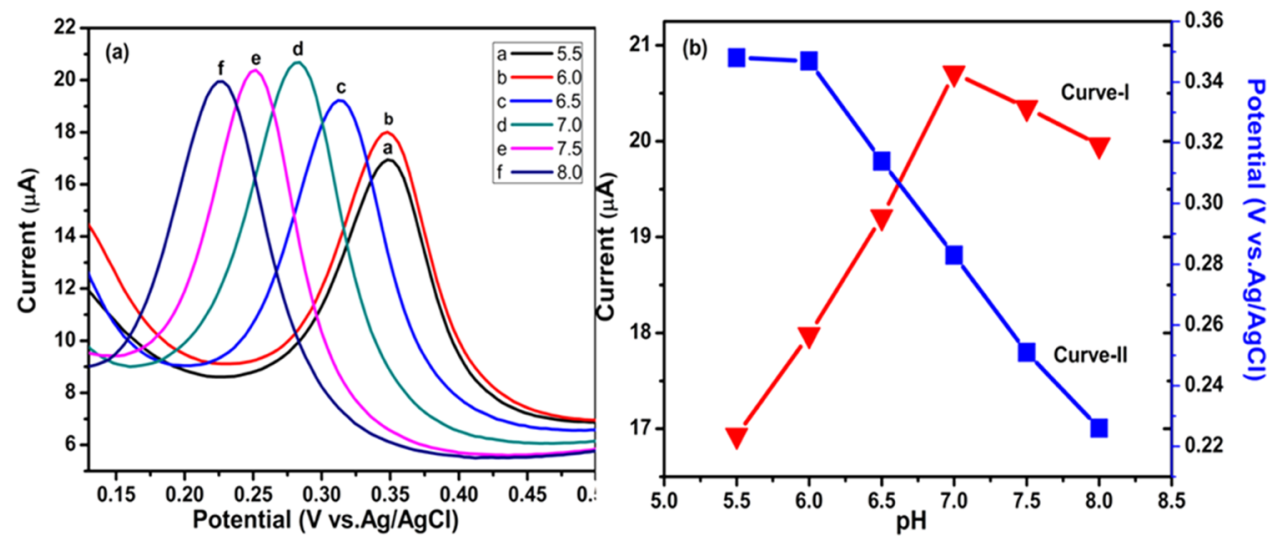

Figure 3. (a) DPV voltammograms obtained with the $\mathrm{ZrO}_{2} / \mathrm{rGO} / \mathrm{GCE}$ in an electrolyte solution at different $\mathrm{pH}$ values, with $0.01 \mathrm{mM}$ REG. (b) Calibration plot of the anodic peak current (curve-I) and the anodic peak potential (curve-II) vs the $\mathrm{pH}$ of the $0.1 \mathrm{M}$ PBS solution, during the electro-oxidation of $0.01 \mathrm{mM} \mathrm{REG}$, at a scan rate of $100 \mathrm{mV} \mathrm{s}^{-1}$. 
Scheme 2. Electrochemical Redox Process of REG by $\mathrm{ZrO}_{2} / \mathrm{rGO} / \mathrm{GCE}$
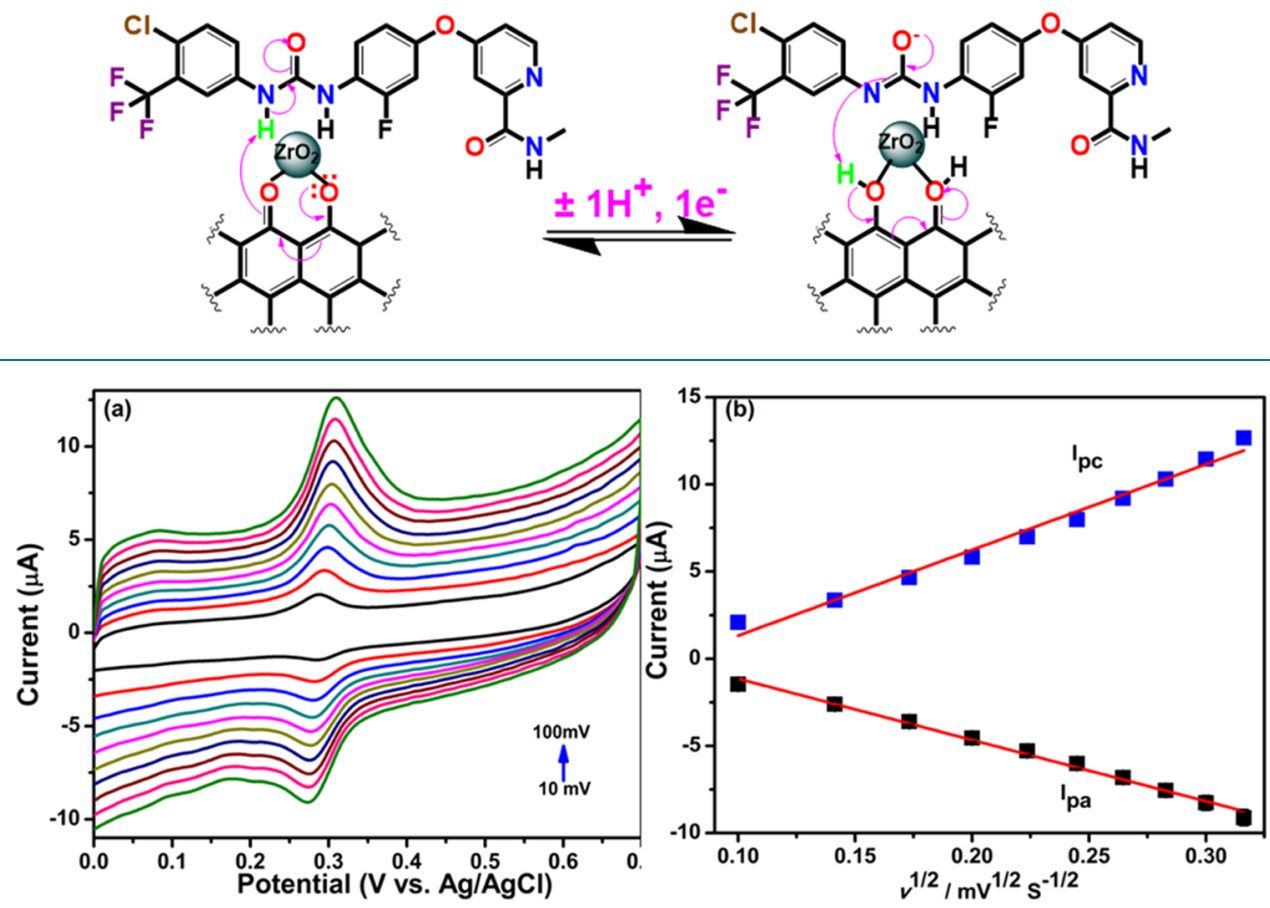

Figure 4. (a) Cyclic voltammograms recorded at the $\mathrm{ZrO}_{2} / \mathrm{rGO} / \mathrm{GCE}$ in the electrolyte solution at different scan rates from 10 to $100 \mathrm{mV} \mathrm{s}{ }^{-1}$. (b) Calibration plot of the anodic and cathode peak currents versus the square root of the scan rate, during the electro-oxidation of $0.01 \mathrm{mM} R E G$ in the presence of $0.1 \mathrm{M}$ PBS, $\mathrm{pH}$ 7.0.
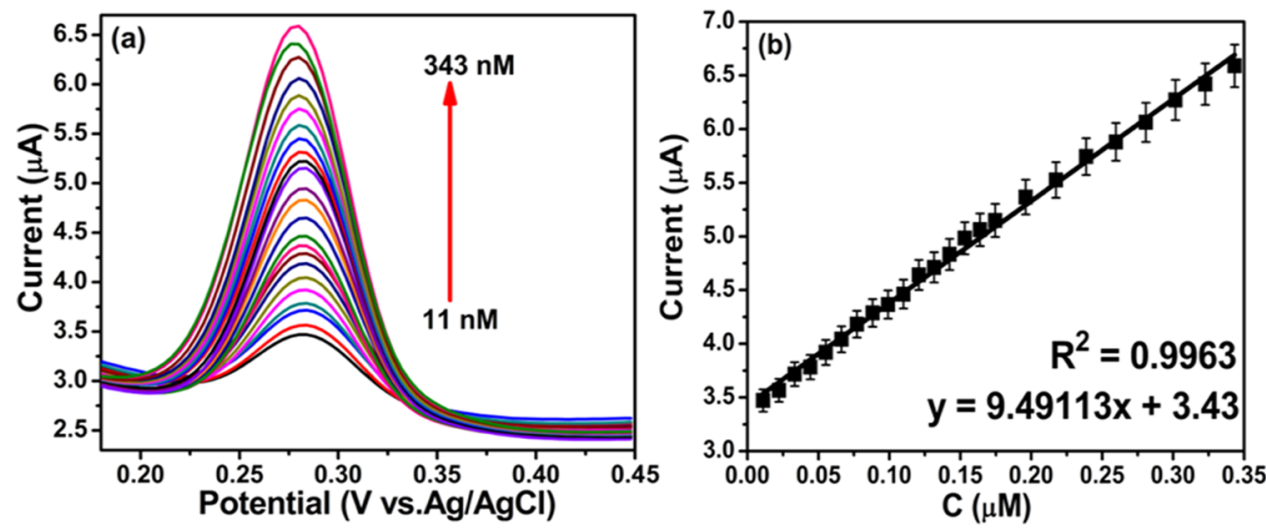

Figure 5. (a) Differential pulse voltammograms recorded at the $\mathrm{ZrO}_{2} / \mathrm{rGO} / \mathrm{GCE}$ over an REG concentration of $11-343 \mathrm{nM}$ in $0.1 \mathrm{M}$ PBS at $\mathrm{pH}$ 7.0. (b) Linear calibration plot of the anodic peak current versus REG concentration.

where $\alpha$ is the electron transfer coefficient (0.76), $n$ is the number of electrons, $F$ is the Faraday constant (96485 C $\left.\mathrm{mol}^{-1}\right), R$ and $T$ are the universal gas constant and temperature $(\mathrm{K})$, respectively, and $k_{\mathrm{s}}$ is the standard heterogeneous rate constant (1.18) determining the slowest step of the REG electrochemical oxidation.

Analytical Performance of $\mathrm{ZrO}_{2} / \mathrm{rGO} / \mathrm{GCE}$ for REG Detection. The $\mathrm{ZrO}_{2} / \mathrm{rGO} / \mathrm{GCE}$ was tested by differential pulse voltammetry (DPV), to investigate the sensitivity of its response to various REG concentrations in the linear dynamic range of 11-343 nM REG in 0.1 M PBS, $\mathrm{pH} \mathrm{7.0,} \mathrm{at} \mathrm{pulse}$ height 60 , pulse width 10 , and scan rate $100 \mathrm{mV} \mathrm{s}^{-1}$, as shown in Figure 5a. The intensity of the anodic peak current increased with the REG concentration. Figure $5 b$ shows the linear dynamic-range plotting of the anodic peak current $\left(I_{\mathrm{pa}}\right)$ versus the REG concentrations and its linear regression equation $I_{\mathrm{pa}}=$
9.4911 (REG) + 3.434, $\left(R^{2}=0.9963\right)$. The limits of detection and quantification can be calculated according to eqs 4 and $5^{45,46}$

$$
\begin{aligned}
& \mathrm{LOD}=3 \times \mathrm{SD} / B \\
& \mathrm{LOQ}=10 \times \mathrm{SD} / B
\end{aligned}
$$

where $\mathrm{SD}$ is the standard deviation and $B$ is the slope of the calibration plot. From the calibration plot, a detection limit of $11 \mathrm{nM}$ and quantification limit of $59 \mathrm{nM}$ were calculated, on the basis of $\mathrm{S} / \mathrm{N}=3$ (signal to noise). These results confirmed that the $\mathrm{ZrO}_{2} / \mathrm{rGO} / \mathrm{GCE}$ is a promising platform for the electrochemical determination of ultratrace of REG concentration.

Simultaneous Detection of REG, AA, and UA by $\mathrm{ZrO}_{2} /$ rGO/GCE. The main objective of this study was sensing of REG, AA, and UA in a mixture. REG, AA, and UA mixture 
solution with different concentrations in $0.1 \mathrm{M}$ PBS with $\mathrm{pH} 7$ was prepared. DPV result for the simultaneous detection of REG, AA, and UA is presented in Figure 6. The oxidation peak

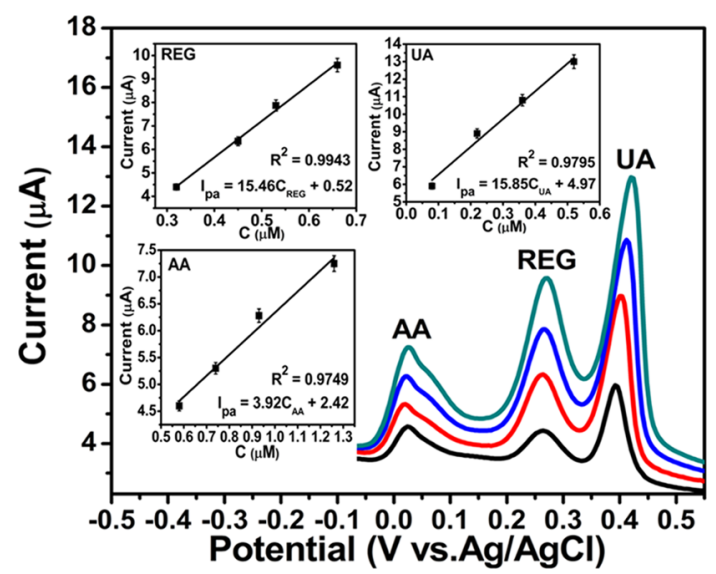

Figure 6. DPVs recorded on the $\mathrm{ZrO}_{2} / \mathrm{rGO} / \mathrm{GCE}$ during simultaneous determination of $0.32-0.66 \mu \mathrm{M}$ REG, $0.58-1.26 \mu \mathrm{M}$ $\mathrm{AA}$, and $0.08-0.52 \mu \mathrm{M}$ UA in $0.1 \mathrm{M} \mathrm{PBS}, \mathrm{pH}$ 7.0. Insets: plots of the anodic peak currents against concentrations of REG, AA, and UA.

current increased synchronously on increasing the concentration of REG, AA, and UA. The DPV signal shows the linear relationship between the oxidation peak current and REG concentrations (Figure 6 inset) with LDR $0.32-0.66 \mu \mathrm{M}$ and the linear regression equation as follows: $I_{\mathrm{pa}}(\mu \mathrm{A})=15.46 C_{\mathrm{REG}}$ $+0.5232(\mu \mathrm{M})\left(R^{2}=0.9943\right)$. The oxidation current increased parallel AA and UA concentrations with LDRs $0.58-1.26$ and 0.08-0.52 $\mu \mathrm{M}$, respectively, and the linear regression equations as follows: $I_{\mathrm{pa}}(\mu \mathrm{A})=3.92 C_{\mathrm{AA}}+2.417(\mu \mathrm{M})\left(R^{2}\right.$ $=0.9749)$ and $I_{\mathrm{pa}}(\mu \mathrm{A})=15.85 C_{\mathrm{UA}}+4.97(\mu \mathrm{M})\left(R^{2}=\right.$ $0.9795)$. This result indicated that the proposed electrochemical sensor enables the synergetic and sensitive detection of REG in the presence of AA and UA without significant interference from each other.

Effect of Interference Compounds. The effect of interferences for the determination of REG, AA, and UA mixture solution was investigated in 0.1 M PBS ( $\mathrm{pH} 7.0$ ) electrolyte solution in the presence of a possible interfering factor such as metal ions $\left(\mathrm{Ca}^{2+}, \mathrm{Mg}^{2+}\right.$, and $\left.\mathrm{Zn}^{2+}\right)$, glutathione, folic acid, or L-cysteine. The observed results are summarized in Table S1. No significant signal intensity change (less than $5 \%$ difference from their original signal intensity) was observed in the presence of interfering ions and molecules. The results indicate that the designed $\mathrm{ZrO}_{2} / \mathrm{rGO} / \mathrm{GCE}$ displays good ability for simultaneous sensing of AA, UA, and REG in a matrix mixture, without any interference of the abovementioned species.

Real-Sample Analysis. The real-sample monitoring of the performance of the $\mathrm{ZrO}_{2} / \mathrm{rGO} / \mathrm{GCE}$ was validated by the DPV determination of REG in human blood serum samples. To determine the accuracy of the results, $1.0 \mathrm{~mL}$ human blood serum samples were diluted 50 times with PBS to prevent the matrix effects of analytical determinations. The human blood serum samples were centrifuged before the measurements; the results are summarized in Table 1 . The recovery rates for the different volumes of the samples ranged between 96.5 and $101.9 \%$ and the relative standard deviations were in the range $0.3-2.4 \%$, showing the accuracy and efficiency of the
Table 1. Real-Sample Analysis of REG Using the Proposed Method by Triplicate $(n=3)$ Readings

\begin{tabular}{ccccc} 
samples & $\begin{array}{c}\text { spiked sample } \\
(\mathrm{mM})\end{array}$ & $\begin{array}{c}\text { found } \\
(\mathrm{mM})\end{array}$ & $\begin{array}{c}\text { recovery } \\
(\%)\end{array}$ & $\begin{array}{c}\text { RSD (\%) } \\
\pm \text { SE }\end{array}$ \\
$\begin{array}{c}\text { pharmaceutical } \\
\text { formulation }\end{array}$ & 0.010 & 0.0098 & 98 & $2.54 \pm 0.05$ \\
& 0.050 & 0.0509 & 101.8 & $1.98 \pm 0.08$ \\
blood serum & 0.100 & 0.0990 & 99 & $1.32 \pm 0.06$ \\
& 0.010 & 0.0098 & 98 & $2.42 \pm 0.11$ \\
& 0.050 & 0.0486 & 97.2 & $1.65 \pm 0.07$ \\
& 0.100 & 0.1026 & 102.6 & $1.09 \pm 0.05$ \\
\hline
\end{tabular}

constructed electrochemical sensor. Therefore, the $\mathrm{ZrO}_{2} /$ rGO/GCE can be applied to real bioclinical samples.

Comparison with Other Established Methods. The sensitivity of the developed electroanalytical method was compared to that of some of the chromatography and spectrophotometry methods. Recently, Fujita et al., reported one method using high-performance liquid chromatography (HPLC) for simultaneous quantitative determination of REG in the human plasma and achieved LOQ of $10 \mathrm{ng} \mathrm{mL}^{-1}$. In addition, Erp et al., reported liquid chromatography tandem mass spectrometry (LC-MS/MS) can achieve LOQ of $100 \mathrm{ng}$ $\mathrm{mL}^{-1}$ for REG. The other spectroscopic method can analyze

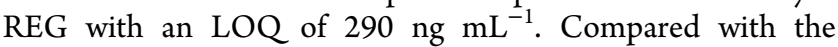
reported methods, the presented method shows a better limit of detection and limit of quantification limit (Table 2). Due to its low cost, simplicity, high sensitivity, and rapid analysis time, the presented method has advantages over the other analytical methods.

\section{CONCLUSIONS}

Inorganic metal-oxide nanoparticles have been enormously employed as electrode material for a developed efficient electrochemical sensor. A simple one-pot hydrothermal synthesis of $\mathrm{ZrO}_{2} / \mathrm{rGO}$ nanocomposite was successfully synthesized. The pristine $\mathrm{ZrO}_{2}$ nanoparticles are about $7 \mathrm{~nm}$ and uniformly dispersed on the reduced graphene oxide sheet. Due to reduced graphene oxide support, the $\mathrm{ZrO}_{2}$ metal-oxide nanoparticles illustrate excellent electrocatalytic performance toward REG anticancer drug. The developed $\mathrm{ZrO}_{2} / \mathrm{rGO}$ nanocomposite was characterized by TEM, EDX, PXRD, FTIR, and XPS measurements. TEM images clearly show the zirconia nanoparticles have uniform size and uniform distribution on the surface of rGO. The inorganic nanocomposite-based electrochemical sensor was successfully applied first time for the detection of REG anticancer drug. The fabricated $\mathrm{ZrO}_{2} / \mathrm{rGO}$ nanocomposite exhibited an excellent electrocatalytic activity toward REG, with a linear dynamic range of $11-343 \mathrm{nM}$ and the detection limit as low as $17 \mathrm{nM}$ toward the detection of REG drug. The $\mathrm{ZrO}_{2} / \mathrm{rGO} /$ GCE was applicable for the joint determination of REG and a commonly reported interference $\mathrm{AA}$ and $\mathrm{UA}$ at $\mathrm{pH}$ 7.0. The calculated LOD/LOQ values by the present electrochemical method are better than those from chromatography and spectrophotometry methods. This electrochemical sensor shows promise for future exploration of rapid detection of other anticancer drugs in human blood serum and pharmaceutical formulation.

\section{EXPERIMENTAL SECTION}

Modification of the Glassy Carbon Electrode. Preparation of the $\mathrm{ZrO}_{2} / \mathrm{rGO} / \mathrm{GCE}$ : prior to use, the bare GCE 
Table 2. Comparison of the Electroanalytical Method with Reported Analytical Techniques

\begin{tabular}{|c|c|c|c|c|}
\hline method & $\mathrm{LDR}\left(\mathrm{ng} \mathrm{mL} \mathrm{m}^{-1}\right)$ & $\mathrm{LOD}\left(\mathrm{ng} \mathrm{mL}^{-1}\right)$ & LOQ (ng mL $\left.{ }^{-1}\right)$ & refs \\
\hline HPLC & $10-10000$ & & 10.0 & 13 \\
\hline LC-MS/MS & $25-25000$ & & 25.0 & 14 \\
\hline LC-MS/MS & $100-4000$ & & 100 & 15 \\
\hline spectrophotometric method & $500-25000$ & 110 & 290 & 20 \\
\hline electroanalytical method & $1.5-107(11-343 \mathrm{nM})$ & $5.00(17 \mathrm{nM})$ & $18.5(59 \mathrm{nM})$ & present work \\
\hline
\end{tabular}

was polished with alumina powder $(1,0.3$, and $0.05 \mu \mathrm{m})$ and washed with an ethanol solution, followed by Millipore water under ultrasonication. For the preparation of the electrochemical sensor, $3 \mathrm{mg}$ of the prepared $\mathrm{ZrO}_{2} / \mathrm{rGO}$ was dispersed in $3 \mathrm{~mL}$ of Millipore water with $0.3 \mathrm{~mL}$ of Nafion solution and then ultrasonicated for $30 \mathrm{~min}$ until a uniformly dispersed ink was obtained. The $\mathrm{ZrO}_{2} / \mathrm{rGO}$ ink $(7 \mu \mathrm{L})$ was drop cast onto the clean GCE surface and allowed to dry for 15 min at room temperature. The $\mathrm{ZrO}_{2} / \mathrm{GCE}$ was fabricated in a similar manner.

Reproducibility and Stability of the Modified Electrode. Reproducibility and stability are key elements for electrode performance. To evaluate the reproducibility of the $\mathrm{ZrO}_{2} / \mathrm{rGO} / \mathrm{GCE}$, we made five sensing electrodes and used them to investigate their CV current response on $1 \mu \mathrm{M}$ REG in phosphate buffered saline (PBS), $\mathrm{pH}$ 7.0, as shown in Figure $\mathrm{S} 1 \mathrm{a}$. The calibrated histograms in Figure S1b show a relatively standard deviation (RSD) of $0.54 \%$. The repeatability of the modified electrochemical sensor values was obtained for the detection of $1 \mu \mathrm{M}$ REG in presence of the supporting electrolyte, PBS ( $\mathrm{pH}$ 7.0). The $\mathrm{ZrO}_{2} / \mathrm{rGO} / \mathrm{GCE}$ average voltammetric response for seven successive determinations was $3.34 \%$ (Figure S2a). Moreover, the stability of the $\mathrm{ZrO}_{2} / \mathrm{rGO} /$ GCE was verified by the daily detection for 7 weeks of $1 \mu \mathrm{M}$ REG solution in presence of the supporting PBS electrolyte ( $\mathrm{pH}$ 7.0). After each test of stability, the electrode was washed with deionized water, dried under an argon stream, and kept in empty glass tubes at room temperature. The electrochemical oxidation of the $1 \mu \mathrm{M}$ REG solution, in presence of the supporting PBS electrolyte ( $\mathrm{pH} 7.0$ ), using the $\mathrm{ZrO}_{2} / \mathrm{rGO} /$ GCE diminished by about $9.6 \%$ of their initial response during the 7 weeks, as shown in Figure S2b. Hence, the proposed method and the modified electrochemical sensor determined REG with higher reproducibility and stability than the $\mathrm{ZrO}_{2}$ / GCE sensor.

Preparation of Real Samples for Analysis. A powdered Stivarga tablet (Nexus Lifecare Pvt. Ltd., Mumbai, India) containing $40 \mathrm{mg}$ of REG was dissolved by ultrasonication in $25 \mathrm{~mL}$ of $0.1 \mathrm{M}$ PBS buffer solution at $\mathrm{pH}$ 7.0. This solution was filtered and quantitatively diluted with buffer solution to get $0.1 \mathrm{mM}$ REG solution that was used for the analyses. Fresh human blood serum samples were collected from healthy volunteers (S. V. University Health Center, S. V. University, Tirupati, India). Approximately, $2.0 \mathrm{~mL}$ of human blood serum

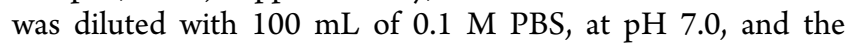
solution thus prepared was used for analysis, without any further treatment.

\section{ASSOCIATED CONTENT}

\section{S Supporting Information}

The Supporting Information is available free of charge on the ACS Publications website at DOI: 10.1021/acsomega.8b02129.
Cyclic voltammogram, EDS data, FT-IR, materials and methods, XPS analysis, XRD, and interferences of some foreign species (PDF)

\section{AUTHOR INFORMATION}

\section{Corresponding Authors}

*E-mail: vinodfcy@gmail.com (V.K.G.).

*E-mail: myyoon@gachon.ac.kr (M.Y.).

*E-mail: gmchem01@gmail.com (G.M.).

ORCID $\odot$

Yenugu Veera Manohara Reddy: 0000-0001-8699-922X

Ankireddy Seshadri Reddy: 0000-0002-0395-3515

Minyoung Yoon: 0000-0001-7436-6273

\section{Author Contributions}

The manuscript was written through contributions of all authors. All authors have given approval to the final version of the manuscript.

Author Contributions

${ }^{\#}$ M.V. and S.V. contributed equally in this work.

Notes

The authors declare no competing financial interest.

\section{ACKNOWLEDGMENTS}

Mr. Manthrapudi Venu is grateful to the UGC Letter No. F. 25-1/2013-14 (BSR)/7-187/2007 (BSR) dated: 19-11-2014 from Government of India, New Delhi, for providing financial assistance in the form of an award of Research Fellowships in Science for meritorious students (RFSMS). This work was also supported by a National Research Foundation of Korea (NRF) grant funded by the Ministry of Science and ICT (NRF2017 R 1 C 1 B 5076834, S.V. and NRF 2018M2A2A6A01057259, M.Y.)

\section{ABBREVIATIONS}

AA, ascorbic acid; CV, cyclic voltammetry; DPV, differential pulse voltammetry; EDX, energy dispersive X-ray spectroscopy; FT-IR, Fourier transform infrared; GCE, glassy carbon electrode; HRTEM, high-resolution transmission electron microscopy; LOD, lower detection limit; LOQ limit of quantifications; REG, regorafenib; rGO, reduced graphene oxide; SAED, selected area electron diffraction pattern; TEM, transmission electron microscopy; UA, uric acid; XPS, X-ray photoelectron spectrometry; XRD, X-ray diffraction; $\mathrm{ZrO}_{2}$ NPs, zirconium oxide nanoparticles

\section{REFERENCES}

(1) Chen, D.; Wei, L.; Yu, J.; Zhang, L. Regorafenib Inhibits Colorectal Tumor Growth Through Puma-Mediated Apoptosis. Clin. Cancer Res. 2014, 20, 3472-3484.

(2) Wilhelm, S. M.; Dumas, J.; Adnane, L.; Lynch, M.; Carter, C. A.; Schutz, G.; Thierauch, K. H.; Zopf, D. Regorafenib (bay 73-4506): A New Oral Multikinase Inhibitor of Angiogenic, Stromal and 
Oncogenic Receptor Tyrosine Kinases with Potent Preclinical Antitumor Activity. Int. J. Cancer 2011, 129, 245-255.

(3) Di Gion, P.; Kanefendt, F.; Lindauer, A.; Scheffler, M.; Doroshyenko, O.; Fuhr, U.; Wolf, J.; Jaehde, U. Clinical Pharmacokinetics of Tyrosine Kinase Inhibitors: Focus on Pyrimidines, Pyridines, and Pyrroles. Clin. Pharmacokinet. 2011, 50, 551603.

(4) Josephs, D. H.; Fisher, D. S.; Spicer, J.; Flanagan, R. Clinical Pharmacokinetics of Tyrosine Kinase Inhibitors: Implications for Therapeutic Drug Monitoring. Ther. Drug Monit. 2013, 35, 562-587.

(5) Ly, J. Q.; Messick, K.; Qin, A.; Takahashi, R. H.; Choo, E. F. Utility of CYP3A4 and PXR-CAR-CYP3A4/3A7 Transgenic Mouse Models to Assess the Magnitude of CYP3A4 Mediated Drug-Drug Interactions. Mol. Pharmaceutics 2017, 14, 1754-1759.

(6) Cheng, A. L.; Kang, Y. K.; Lin, D. Y.; Park, J. W.; Kudo, M.; Qin, S.; Chung, H. C.; Song, X.; Xu, J.; Poggi, G.; Omata, M.; Pitman Lowenthal, S.; Lanzalone, S.; Yang, L.; Lechuga, M. J.; Raymond, E. Sunitinib Versus Sorafenib in Advanced Hepatocellular Cancer: Results of a Randomized Phase III Trial. J. Clin. Oncol. 2013, 31, 4067-4075.

(7) Cheng, A. L.; Kang, Y. K.; Chen, A. L.; Tsao, Z.; Qin, C. J.; Kim, S.; Luo, J. S.; Feng, R.; Ye, J.; Yang, S.; Xu, T. S.; Sun, J.; Liang, Y.; Liu, H.; Wang, J.; Tak, J.; Pan, W. Y.; Burock, H.; Zou, K.; Voliotis, J.; Guan, D. Z. Efficacy, and Safety of Sorafenib in Patients in the AsiaPacific Region with Advanced Hepatocellular Carcinoma: A Phase III Randomized, Double-Blind, Placebo-Controlled Trial. Lancet Oncol. 2009, 10, 25-34.

(8) Hutson, T. E.; Escudier, B.; Esteban, E.; Bjarnason, G. A.; Lim, H. Y.; Pittman, K. B.; Senico, P.; Niethammer, A.; Lu, D. R.; Hariharan, S.; Motzer, R. J. Randomized Phase III Trial of Temsirolimus versus Sorafenib as Second-Line Therapy after Sunitinib in Patients with Metastatic Renal Cell Carcinoma. J. Clin. Oncol. 2014, 32, 760-767.

(9) Grothey, A.; Van Cutsem, E.; Sobrero, A.; Siena, S.; Falcone, A.; Ychou, M.; Humblet, Y.; Bouché, O.; Mineur, L.; Barone, C.; Adenis, A.; Tabernero, J.; Yoshino, T.; Lenz, H. J.; Goldberg, R. M.; Sargent, D. J.; Cihon, F.; Cupit, L.; Wagner, A.; Laurent, D. Correct Study Group, Regorafenib Monotherapy for Previously Treated Metastatic Colorectal Cancer (Correct): An International, Multicentre, Randomised, Placebo-Controlled, Phase III Trial. Lancet 2013, 381, 303312.

(10) Escudier, B.; Eisen, T.; Stadle, W. M.; Szczylik, C.; Oudard, S.; Siebels, M.; Negrier, S.; Chevreau, C.; Solska, E.; Desai, A. A.; et al. Sorafenib in Advanced Clear-Cell Renal-Cell Carcinoma. N. Engl. J. Med. 2007, 356, 125-134.

(11) Mross, K.; Frost, A.; Steinbild, S.; Hedbom, S.; Buchert, M.; Fasol, U.; Unger, C.; Kratzschmar, J.; Heinig, R.; Boix, O.; Christensen, O. A Phase I Dose-Escalation Study of Regorafenib (BAY 73-4506), an Inhibitor of Oncogenic, Angiogenic, and Stromal Kinases, in Patients with Advanced Solid Tumors. Clin. Cancer Res. 2012, 18, 2658-2667.

(12) Crona, D. J.; Keisler, M. D.; Walko, C. M. Regorafenib: A Novel Multitargeted Tyrosinekinase Inhibitor for Colorectal Cancer and Gastrointestinal Stromal Tumors. Ann. Pharmacother. 2013, 47, 1685-1696.

(13) Fujita, K.; Miura, M.; Shibata, H. Quantitative Determination of Regorafenib and its Two Major Metabolites in Human Plasma with High-Performance Liquid Chromatography and Ultraviolet Detection. Biomed. Chromatogr. 2016, 30, 1611-1617.

(14) Luethi, D.; Durmus, S.; Schinkel, A. H.; Schellens, J. H. M.; Beijnen, J. H.; Sparidans, R. W. Liquid Chromatography-Tandem Mass Spectrometric Assay for the Multikinase Inhibitor Regorafenib in Plasma. Biomed. Chromatogr. 2014, 28, 1366-1370.

(15) van Erp, N. P.; Wit, D. D.; Guchelaar, H. J.; Gelderblom, H.; Hessing, T. J.; Hartigh, J. D. A Validated Assay for the Simultaneous Quantification of Six Tyrosine Kinase Inhibitors and Two Active Metabolites in Human Serum Using Liquid Chromatography Coupled with Tandem Mass Spectrometry. J. Chromatogr. B 2013, 937, 33-43.
(16) Hafner, F.-T.; Werner, D.; Kaiser, M. Determination of Regorafenib (Bay 73- 4506) and its Major Human Metabolites Bay 75-7495 (M-2) and Bay 81-8752 (M-5) in Human Plasma by StableIsotope Dilution Liquid Chromatography-Tandem Ms. Bioanalysis 2014, 6, 1923-1937.

(17) Merienne, C.; Rousset, M.; Ducint, D.; Castaing, N.; Titier, K.; Molimard, M.; Bouchet, S. High Throughput Routine Determination of 17 Tyrosine Kinase Inhibitors by LC-MS/MS. J. Pharm. Biomed. Anal. 2018, 150, 112-120.

(18) Pang, Y. Y.; Tan, Y. L.; Ho, H. K. Investigation of the Effect of Plasma Albumin Levels on Regorafenib-Induced Hepatotoxicity Using A Validated Liquid Chromatography-Tandem Mass Spectrometry Method. J. Chromatogr. B 2017, 1061-1062, 220-224.

(19) Allard, M.; Khoudour, N.; Rousseau, B.; Joly, C.; Costentin, C.; Blanchet, B.; Tournigand, C.; Hulin, A. Simultaneous Analysis of Regorafenib and Sorafenib and Three of their Metabolites in Human Plasma Using LC-MS/MS. J. Pharm. Biomed. Anal. 2017, 142, 4248.

(20) Albayrak, M. Development and Validation of a New Spectrophotometric Method for the Determination of Regorafenib in Pure and Tablet Dosage Form. Lat. Am. J. Pharm. 2018, 37, 13491353.

(21) Ma, Z.; Chen, P.; Cheng, W.; Yan, K.; Pan, L.; Shi, Y.; Guihua, Y. Highly Sensitive, Printable Nanostructured Conductive Polymer Wireless Sensor for Food Spoilage Detection. Nano Lett. 2018, 18, $4570-4575$.

(22) Ngo, Y. H.; Brothers, M.; Martin, J. A.; Grigsby, C. C.; Fullerton, K.; Naik, R. R.; Kim, S. S. Chemically Enhanced PolymerCoated Carbon Nanotube Electronic Gas Sensor for Isopropyl Alcohol Detection. ACS Omega 2018, 3, 6230-6236.

(23) Hou, H.; Tingting, X.; Yang, W.; Shengjun, L.; Chu, R.; Zhang, J.; Liu, B. Conductive and Chiral Polymer-Modified Metal-Organic Framework for Enantioselective Adsorption and Sensing. ACS Appl. Mater. Interfaces 2018, 10, 26365-26371.

(24) Reddy, Y. V. M.; Sravani, B.; Fernandes, D. M.; Madhuri, Ch.; Subramanyam Sarma, L.; Madhavi, G. Facile One-Pot Synthesis of Bimetallic Pd-Ag/Reduced Graphene Oxide Nanocomposite as an Electrochemical Sensor for Sensitive Detection of Antihypotensive Drug. Colloids Surf., A 2018, 546, 293-300.

(25) Reddy, Y. V. M.; Bathinapatla, S.; Łuczak, T.; Osinska, M.; Maseed, H.; Ragavendhra, P.; Sarma, L. S.; Srikanth, V. V. S. S.; Madhavi, G. An Ultra-Sensitive Electrochemical Sensor for the Detection of Acetaminophen in the Presence of Etilefrine using Bimetallic Pd-Ag/Reduced Graphene Oxide Nanocomposites. New J. Chem. 2018, 42, 3137-3146.

(26) Reddy, Y. V. M.; Sravani, B.; Agarwal, S.; Guptha, V. K.; Madhavi, G. Electrochemical Sensor for Detection of Uric acid in the Presence of Ascorbic acid and Dopamine Using the Poly (Dpa)/ Sio2@Fe3o4 Modified Carbon Paste Electrode. J. Electroanal. Chem. 2018, 820, 168-75.

(27) Sağlam, Ş.; Aysem, U. Z.; Erol, E.; Resat, A. Electrochemical Determination of TNT, DNT, RDX, and HMX with Gold Nanoparticles/Poly (Carbazole-Aniline) Film-Modified Glassy Carbon Sensor Electrodes Imprinted for Molecular Recognition of Nitroaromatics and Nitramines. Anal. Chem. 2018, 90, 7364-7370.

(28) Li, L.; Chen, M.; Huang, G.; Yang, N.; Zhang, L.; Wang, H.; Liu, Y.; Wang, W.; Gao, J. A Green Method to Prepare Pd-Ag Nanoparticles Supported on Reduced Graphene Oxide and Their Electrochemical Catalysis of Methanol and Ethanol Oxidation. J. Power Sources 2014, 263, 13-21.

(29) Mazloum-Ardakani, M.; Hosseinzadeh, L.; Taleat, Z. Synthesis and Electrocatalytic Effect of Ag@Pt Core-Shell Nanoparticles Supported on Reduced Graphene Oxide for Sensitive and Simple Label-Free Electrochemical Aptasensor. Biosens. Bioelectron. 2015, 74, $30-36$.

(30) Sawangphruk, M.; Srimuk, P.; Chio-chan, P.; Krittayavathananon, A.; Luanwuthi, S.; Limtrakul, J. Limtrakul. the High-Performance Supercapacitor of Manganese Oxide/Reduced 
Graphene Oxide Nanocomposite Coated on Flexible Carbon Fiber Paper. Carbon 2013, 60, 109-116.

(31) Jayakumar, K.; Camarada, M. B.; Venkataraman, D.; Rajendiran, R.; Rengarajan, V.; Huangxian, J.; Mahalingam, M.; Abhishek, R.; Sudipta, R. B.; Yangping, W. Layer-by-Layer-Assembled AuNPs-Decorated First-Generation Poly (amidoamine) Dendrimer with Reduced Graphene Oxide Core as Highly Sensitive Biosensing Platform with Controllable 3D Nanoarchitecture for Rapid Voltammetric Analysis of Ultratrace DNA Hybridization. ACS Appl. Mater. Interfaces 2018, 10, 21541-21555.

(32) Karthik, P.; Vinoth, R.; Zhang, P.; Wonyong, C.; Balaraman, E.; Neppolian, B. $\pi-\pi$ Interaction Between Metal-Organic Framework and Reduced Graphene Oxide for Visible-Light Photocatalytic $\mathrm{H}_{2}$ Production. ACS Appl. Energy Mater. 2018, 1, 1913-1923.

(33) Srinivasan, V.; Mariadoss, A. J.; Kathiresan, M.; Arunkumar, K. Nanostructured Graphene Oxide Dots: Synthesis, Characterization, Photoinduced Electron Transfer Studies, and Detection of Explosives/Biomolecules. ACS Omega 2018, 3, 9096-9104.

(34) Dong, X. C.; Xu, H.; Wang, X. W.; Huang, Y. X.; Chan-Park, M. B.; Zhang, H.; Wang, L. H.; Huang, W.; Chen, P. 3D GrapheneCobalt Oxide Electrode for High Performance Supercapacitor and Enzymeless Glucose Detection. ACS Nano 2012, 6, 3206-3213.

(35) Yang, Y.; Wang, Z.; Yang, M.; Li, J.; Zheng, F.; Shen, G.; Yu, R. Electrical Detection of Deoxyribonuclic acid Hybridization Based on Carbon-Nanotubes/Nanozirconium Dioxide/Chaitozen-Modified Electrode. Anal. Chim. Acta. 2007, 584, 268-274.

(36) Chen, A.; Zhou, Y.; Ta, N.; Li, Y.; Shen, W. Redox Properties and Catalytic Performance of Ceria-Zirconia Nanorods. Catal. Sci. Technol. 2015, 5, 4184-4192.

(37) Kumar, S.; Kumar, S.; Srivastava, S.; Yadav, B. K.; Lee, S. H.; Sharma, J. G.; Doval, D. C.; Malhotra, B. D. Reduced Graphene Oxide Modified Smart Conducting Paper for Cancer Biosensor. Biosens. Bioelectron. 2015, 73, 114-122.

(38) Zhao, N.; Pan, D.; Nie, W.; Ji, X. Two-Phase Synthesis of Shape-Controlled Colloidal Zirconia Nanocrystals and their Characterization. J. Am. Chem. Soc. 2006, 128, 10118-10124.

(39) Vilian, A. T. E.; Chen, S. M.; Huang, L. H.; et al. Simultaneous Determination of Catechol and Hydroquinone Using a $\mathrm{Pt} / \mathrm{ZrO}_{2}-$ rGO/GCE Composite Modified Glassy Carbon Electrode. Electrochim. Acta 2014, 125, 503-509.

(40) Kumar, S.; Sharma, J. G.; Maji, S.; Malhotra, B. D. Nanostructured Zirconia Decorated Reduced Graphene Oxide Based Efficient Biosensing Platform for Non-Invasive Oral Cancer Detection. Biosens. Bioelectron. 2016, 78, 497-504.

(41) Gupta, P. K.; Sachchidanand, T.; Zishan, H. K.; Pratima, S. R. Amino Acid Functionalized $\mathrm{ZrO}_{2}$ Nanoparticles Decorated Reduced Graphene Oxide Based Immunosensor. J. Mater. Chem. B 2017, 5, 2019-2033.

(42) Raj, M.; Gupta, P.; Goyal, R. N.; Shim, Y. B. Graphene/ Conducting Polymer Nano-Composite Loaded Screen-Printed Carbon Sensor for Simultaneous Determination of Dopamine and 5-Hydroxytryptamine. Sens. Actuators, B 2017, 239, 993-1002.

(43) Mahmoud, B. G.; Khairy, M.; Rashwan, A. F.; Banks, C. E. Simultaneous Voltammetric Determination of Acetaminophen and Isoniazid (Hepatotoxicity-Related Drugs) Utilizing Bismuth Oxide Nanorod Modified Screen-Printed Electrochemical Sensing Platforms. Anal. Chem. 2017, 89, 2170-2178.

(44) Laviron, E. General Expression of the Linear Potential Sweep Voltammogram in the Case of Diffusion less Electrochemical Systems. J. Electroanal. Chem. Interfacial Electrochem. 1979, 101, 19-28.

(45) Fan, Y.; Liu, J. H.; Lu, H. T.; Zhang, Q. Electrochemical Behavior and Voltammetric Determination of Paracetamol on Nafion/ $\mathrm{TiO}_{2}-$ Graphene Modified Glassy Carbon Electrode. Colloids Surf., B 2011, 85, 289-292.

(46) Xu, C. X.; Huang, K. J.; Fan, Y.; Wu, Z. W.; Li, J. Electrochemical Determination of Acetaminophen Based on $\mathrm{TiO}_{2}-$ Graphene/Poly (Methyl Red) Composite Film Modified Electrode. J. Mol. Liq. 2012, 165, 32-37. 